\title{
Neoadjuvant chemotherapy in borderline resectable pancreatic cancer: A case report
}

\author{
MARIA CELESTE PALMAROCCHI ${ }^{1}$, RUBEN CARLO BALZAROTTI CANGER ${ }^{2}$ and PIERCARLO SALETTI ${ }^{1}$ \\ ${ }^{1}$ Medical Oncology, Oncology Institute of Southern Switzerland, 6500 Bellinzona; \\ ${ }^{2}$ Department of Surgery, Lugano Regional Hospital, 6900 Lugano, Switzerland
}

Received August 11, 2016; Accepted January 11, 2017

DOI: $10.3892 / \mathrm{ol} .2017 .6026$

\begin{abstract}
Pancreatic cancer is the fourth leading cause of cancer mortality and is associated with a poor overall survival even when diagnosed early and considered resectable. Complete surgical removal with negative histological margins is an independent predictor of survival and remains the only potential curative treatment. In borderline resectable pancreatic adenocarcinoma (BRPAC), preoperative systemic therapy may increase resectability and margin-negative resection rate. There is no current consensus on the optimal chemotherapy regimen for BRPAC. The present case describes a patient with BRPAC who achieved a pathological complete response to neoadjuvant FOLFIRINOX (folinic acid, fluorouracil, irinotecan and oxaliplatin), but early relapse following a pancreaticoduodenectomy without vascular resection, with an uneventful postoperative course, except for a pulmonary embolism.
\end{abstract}

\section{Introduction}

Over the past decade, the incidence of pancreatic adenocarcinoma (PAC) has been increasing, and it accounts for $2.8 \%$ of new malignancies and $6.2 \%$ of all cancer mortalities, and is the fourth leading cause of cancer-associated mortality in the United States, according to the American Cancer Society $(1,2)$. The 5-year relative overall survival (OS) rate is $6 \%$, with a low level of improvement over the previous 3 decades compared to other types of tumors $(1,2)$. Surgical resection is the only potential curative treatment. Poor prognosis is mainly associated with late diagnosis, low resection rate and aggressiveness of neoplasia. PAC presents as locally advanced (LAPAC) or metastatic in the majority of patients; thus, only $10-20 \%$ of patients are eligible for curative surgery (2).

Correspondence to: Dr Maria Celeste Palmarocchi, Medical Oncology, Oncology Institute of Southern Switzerland, Via Ospedale 1, 6500 Bellinzona, Switzerland

E-mail: mariaceleste.palmarocchi@eoc.ch

Key words: review, pancreatic cancer, neoadjuvant therapy, FOLFIRINOX, pathological complete response
For many years, physicians have largely ignored the tumor node metastasis staging system (3) to categorize patients into three different groups: resectable, LA and metastatic PAC. At present, with improved imaging techniques and a renewed focus on surgical expertise, a fourth category has been proposed: borderline resectable (BRPAC). These patients must be identified a priori, as the goals of treatment differ from those in patients with truly unresectable PAC (4). Numerous anatomic definitions of BRPAC have been proposed, with the greatest points of contention revolving around the extent of involvement of the superior mesenteric vein (SMV) (5-7).

More effective systemic regimens, compared with single agent gemcitabine treatment, have emerged in the treatment of PAC. Large randomized trials of FOLFIRINOX (folinic acid, fluorouracil, irinotecan and oxaliplatin), or gemcitabine with nanoparticle albumin-bound (nab)-paclitaxel have revealed significantly improved overall survival (OS) and response rates (RRs) compared with those associated with single-agent gemcitabine $(8,9)$. An increasing level of evidence supports the use of neoadjuvant strategies aiming to control micrometastatic disease, induce tumor shrinkage and achieve resection for cure/complete remission (R0).

\section{Case report}

In September 2014, a 58-year-old female patient was presented at the Lugano Regional Hospital (Lugano, Switzerland) with long-lasting diabetes, abdominal pain and weight loss. The Eastern Cooperative Oncology Group performance status was 1 , and laboratory parameters were normal, with the exception of carbohydrate antigen (CA) 19-9, which was 149.2 U/ml (normal range: $<35.4 \mathrm{U} / \mathrm{ml}$ ), and carcinoembryonic antigen, which was $59.1 \mathrm{ng} / \mathrm{ml}$ (normal range $<3.0 \mathrm{ng} / \mathrm{ml}$ ). A computed tomography (CT) scan revealed a $3.7-\mathrm{cm}$ mass in the pancreatic head, encasing the porto-mesenteric axis $\geq 180^{\circ}$, with narrowing and almost complete short segment occlusion of the SMV, and superior mesenteric artery (SMA) abutment (Fig. 1A and B). There was no evidence of lymph node involvement or visceral metastatic spread. The result of an endoscopic ultrasound-guided fine needle biopsy was concordant with adenocarcinoma, and the patient was diagnosed with BRPAC.

FOLFIRINOX (oxaliplatin $85 \mathrm{Mg} / \mathrm{m}^{2}$, leucovorin $400 \mathrm{Mg} / \mathrm{m}^{2}$, irinotecan $180 \mathrm{Mg} / \mathrm{m}^{2}$ and 5-FU $400 \mathrm{Mg} / \mathrm{m}^{2}$ bolus 
then $2,400 \mathrm{Mg} / \mathrm{m}^{2}$ over $48 \mathrm{~h}$, all on day 1 , and then repeated every 2 weeks), was administered to the patient for 3 months. No severe side effects occurred except mild asthenia and no dose reductions were applied. The patient experienced symptom improvement, the tumor markers levels reduced to the normal levels and the follow-up CT scan revealed a marked tumor reduction. As porto-mesenteric infiltration was no longer observed (Fig. 2A and B), a surgical exploration was planned.

In February 2015, the patient underwent a pyloruspreserving cephalic duodenopancreatectomy without vascular resection, since neither visceral spread nor arterial infiltration were observed intra-operatively. No macroscopic evidence of tumor was observed. A fibrous-like tissue was observed and the entire specimen was sent for microscopic examination. Neither residual tumor cells nor metastases in 14 regional lymph nodes were detected, and the surgical margins were negative. These findings were consistent with a pathological complete response (pCR). Pulmonary embolism occurred postoperatively, but the patient fully recovered. Adjuvant chemotherapy was suggested, but the patient refused due to a general worsening of condition following surgery. In June 2015, the patient complained of abdominal discomfort, and a CT scan revealed multiple hepatic metastasis. Chemotherapy with gemcitabine and nab-paclitaxel was administered for 2 months, but the disease progressed and the patient succumbed to the disease in October 2015. The patient gave us oral and written informed consent prior submission of the manuscript.

\section{Discussion}

BRPAC is a novel entity characterized by the limited involvement of the superior mesenteric vessels (SMA and SMV), celiac axis and hepatic artery. Although skill-demanding, resection is technically feasible in BRPAC, but is associated with a high risk of positive margins and, consequently, of early recurrence (6). The present case describes a patient with BRPAC who achieved pCR subsequent to neoadjuvant FOLFIRINOX, but relapsed following surgery. The present case raises certain issues.

Firstly, a multidisciplinary approach is required to properly assess the resectability of the PAC. There are unresolved issues with respect to the definition of BRPAC, including how much of the SMV or major visceral arteries must be surrounded on CT scan to diagnose BR or LA unresectable, or whether or not the requirement to replace a segment of vein defines resectability. SMV, SMA, celiac artery and hepatic artery involvement have been identified as an anatomic point of contention, and numerous definitions have been proposed $(5-7,10)$. The patient in the present case was classified as BRPAC based on porto-mesenteric involvement, segmental SMV occlusion and SMA abutment.

Modern imaging techniques allow accurate preoperative staging, although there is no definite consensus on the most preferable approach. CT scans are $\sim 80 \%$ accurate with respect to predicting resectability and almost $90 \%$ accurate in assessing vascular invasion (11). In experienced hands, accuracy of endoscopic ultrasound is $75-95$ and $74-87 \%$ in assessing $\mathrm{T}$ and $\mathrm{N}$ stages, respectively (12-14). Endoscopic ultrasound is particularly useful in identifying lesions $<2 \mathrm{~cm}$, and may characterize the presence of vascular invasion or venous thrombosis (12-14). There are limited data on the role of positron emission tomography (PET)/CT in the staging of potentially resectable tumors. In a retrospective series, PET/CT has been shown to change the management in $17 \%$ of patients with BRPAC and $7 \%$ with resectable PAC $(\mathrm{P}=0.019)$, ultimately preventing unnecessary surgery (15). The accuracy of imaging in determining resectability has also been evaluated in patients with BRPAC who underwent neoadjuvant therapy, and response evaluation criteria in solid tumors (RECIST) criteria resulted unreliable to select patients for surgery (16). Although only $0.8 \%$ of patients experienced downstaging to resectable status subsequent to receiving neoadjuvant therapy, $66 \%$ of patients underwent pancreatectomy. The OS for 129 patients was 22 months, whilst the OS of the patients who underwent pancreatectomy was 33 months and was not correlated with RECIST response $(\mathrm{P}=0.78)(16)$. In a different study, neoadjuvant FOLFIRINOX resulted in a significant decrease in tumor size, however $47 \%$ of patients with BRPAC or LAPAC remained classified as unresectable. However, $92 \%$ of the patients underwent an R0 resection, suggesting that traditional imaging no longer predicts unresectability (17). Thus, it may be speculated that hyperdensity surrounding the major vessels considered to be neoplastic becomes, or was initially, fibrotic, possibly explaining the absence of radiological changes.

Secondly, besides overall health status, the presence of significant comorbidities and nutritional deficiency (18), understanding tumor biology may assist clinicians in selecting patients for surgery. No validated prognostic biomarkers predict recurrence following resection. A study evaluated the association between CA 19-9 and surgical outcomes in BRPAC (19). Normalization of CA 19-9 following neoadjuvant therapy was associated with longer OS in resected (38 vs. 26 months, $\mathrm{P}=0.020$ ) and unresected ( 15 vs. 11 months, $\mathrm{P}=0.022$ ) patients. Conversely, failure of CA 19-9 to normalize was revealed to be an independent factor of shorter OS [hazard ratio $(\mathrm{HR})=2.13 ; \mathrm{P}=0.001$ ]

Patients exhibiting wild-type SMAD family member 4 (SMAD4) gene were shown to display a lower propensity for metastases than those exhibiting the loss of SMAD4 (20). However, a different study failed to demonstrate an association between SMAD4 messenger RNA expression and OS (21). Secreted protein acidic and cysteine rich (SPARC) is a glycoprotein expressed by stromal cells surrounding the tumor, and is involved in cell migration and tissue remodeling (20). Patients who expressed SPARC in tumor stroma exhibited a significantly worse prognosis than those who did not (median OS, 15 vs. 30 months; $\mathrm{P}<0.001)$ (22), a result that has been supported by additional studies $(23,24)$. SPARC is known to bind to albumin (25). By binding to SPARC inside the extracellular matrix, nab-paclitaxel successfully disrupts the organization of tumor cells and induces a marked alteration in tumor architecture, resulting in increased tumor softening and permeability (25). In human epidermal growth factor receptor 2-positive tumors, nab-paclitaxel was shown to be equivalent or even superior to polysorbate-based docetaxel in tumors with medium to high SPARC levels (26).

PAC cells overexpress epidermal growth factor receptor, and previous studies have demonstrated correlations between 

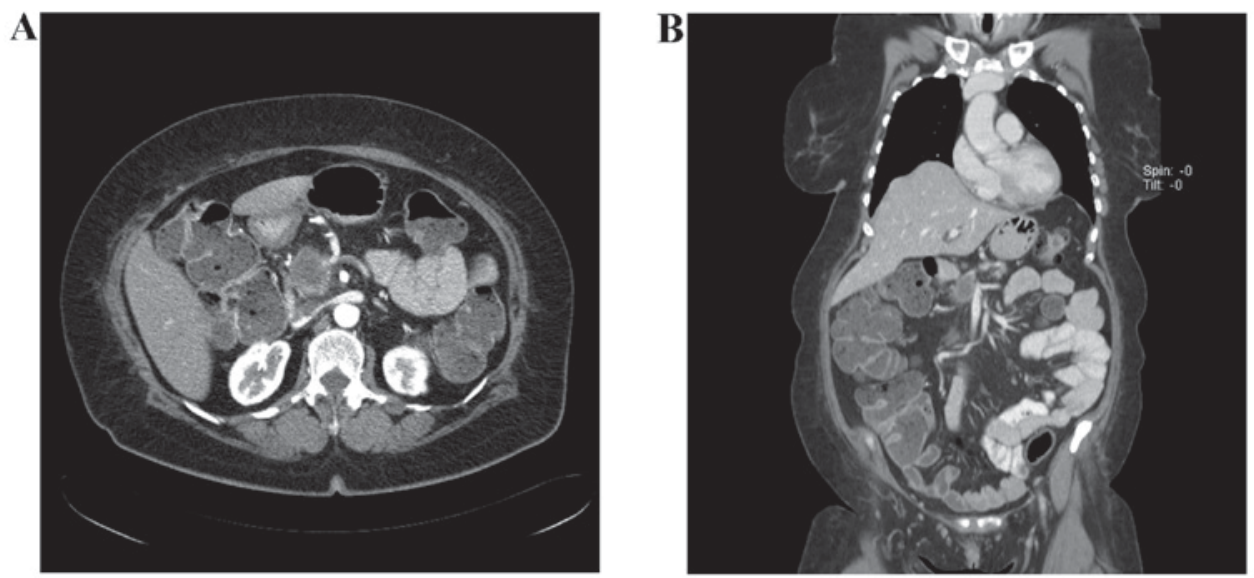

Figure 1. (A) Axial plane and (B) coronal plane computed tomography scan prior to neoadjuvant chemotherapy, showing radiological signs of a borderline resectable lesion: e.g. Encasement/short segment occlusion of the superior mesenteric vein and tumor abutment of the superior mesenteric artery.
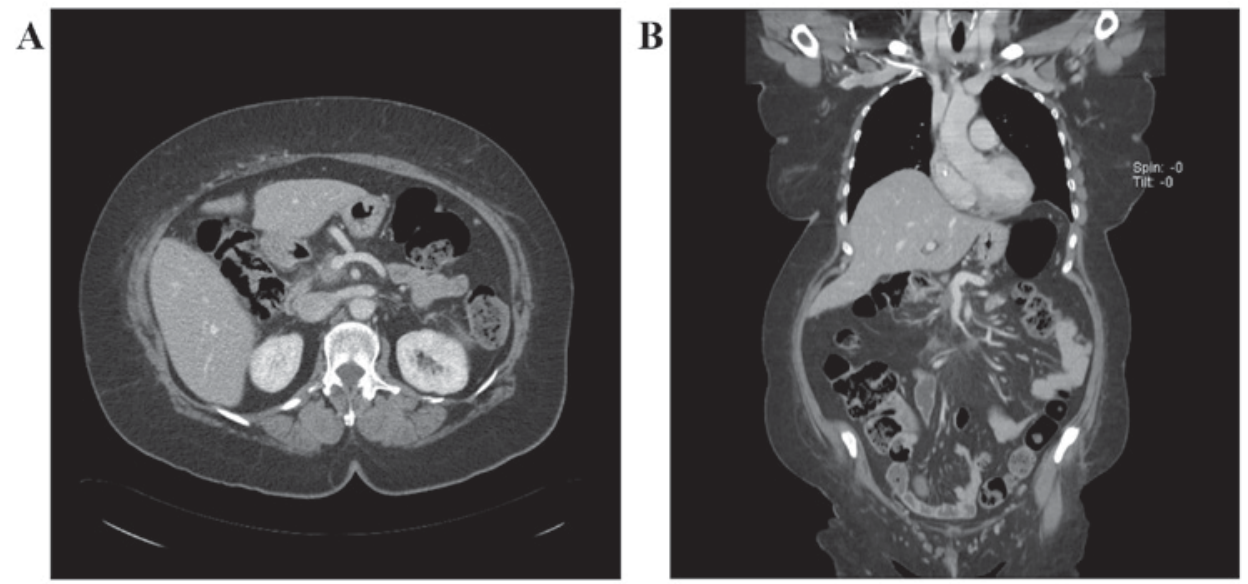

Figure 2. (A) Axial plane and (B) coronal plane computed tomography scan subsequent to neoadjuvant chemotherapy, showing radiological sings of the cancer's response to chemotherapy: e.g. Tumor shrinkage and recanalization of superior mesenteric vein.

receptor/ligand co-expression and larger tumors, advanced stage and decreased OS $(27,28)$. Thymidylate synthase (TS) has been evaluated in 132 resected patients, and the median OS resulted improved in those with low TS expression compared with patients exhibiting high TS expression, which resulted in TS being an independent predictor of mortality at multivariate analysis (29). However, a similar study investigating TS expression reported conflicting results (30). Finally, non-coding RNAs have been observed to be deregulated in numerous types of human cancer. Studies have shown that non-coding RNAs affect the progression of PAC, and RNA profiling may assist the prediction of outcomes with high accuracy (31).

Thirdly, the present case reflects the growing recognition accorded to neoadjuvant strategies to improve OS in pancreatic cancer, a highly fatal disease. The main potential advantages of neoadjuvant strategies are: i) increased resectability and likelihood of margin-negative resection, which is relevant, as patients with BRPAC or LAPAC exhibit a similar prognosis to those with immediately resectable PAC if $\mathrm{R} 0$ resection can be achieved (10); ii) increased likelihood of completion of multimodal treatment, which is possibly the most effective way to improve the outcome of patients with BRPAC or
LAPAC; iii) prevention of unnecessary surgery in aggressive, treatment-resistant disease; iv) evaluation of chemo-sensitivity and increased patient's compliance (32); v) minimization of pancreatic leak without increase of postoperative complications (33-37); and vi) cost-effectiveness (38).

With regards to chemotherapy, the optimal neoadjuvant regimen has not been established to date, as current evidence arises from small, single-institution, non-randomized trials. These studies are difficult to interpret, as they have used various definitions of BRPAC, different induction and post-resection regimens, and, if applied, incorporated varied radiation therapy plans (38-42). The most active regimens for advanced disease offer the best chance of achieving downstaging and systemic disease control. FOLFIRINOX regimen resulted in a statistically significant increase in OS (11.1 vs. 6.8 months; $\mathrm{P}<0.001)$ and RR (31.6 vs. 9.4\%; $\mathrm{P}<0.001)$ compared with the results observed with gemcitabine in patients with metastatic disease (6). Thus, FOLFIRINOX has been incorporated in neoadjuvant trials for BRPAC and LAPAC (Table I), either alone or in combination with chemoradiation (43-59).

In a meta-analysis of 13 of the aforementioned studies involving 253 patients, resection rate and $\mathrm{R} 0$ resection were 


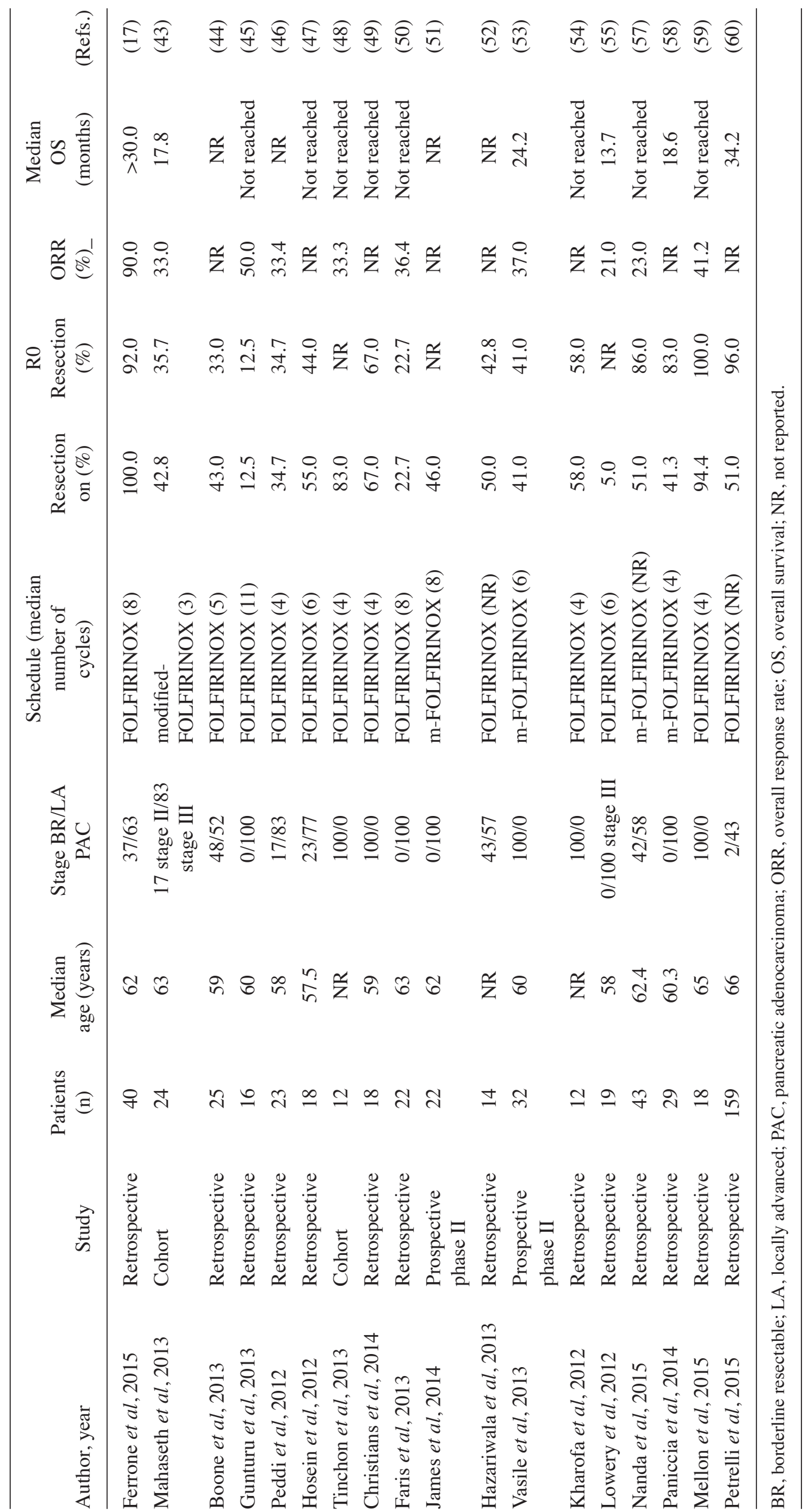


achieved in 43.0 and $39.4 \%$ of patients, respectively. R0 resection was possible in $63.5 \%$ of patients with BRPAC and $22.5 \%$ of patients with LAPAC (60). Three trials reported an OS between 13.7 and 24.2 months (60), compared with the OS of $\sim 2$ years of patients who complete adjuvant therapy subsequent to upfront surgery $(61,62)$.

In the single-arm pilot study Alliance A021101, 22 patients with BRPAC were treated with 4 cycles of modified FOLFIRINOX (FOLFIRINOX without fluorouracil bolus) followed by chemoradiation prior to pancreatectomy, and an additional 2 cycles of adjuvant gemcitabine. In total, $68 \%$ of patients underwent pancreatectomy, and of those patients, R0 resection was achieved for $93 \%$ while pCR was observed in 9\% (63). The single-arm phase IIa Pancreatic Resectability in Cancers with Known Limited Extension trial is currently ongoing, and evaluates gemcitabine and nab-paclitaxel in a neoadjuvant setting (64). FOLFIRINOX exhibits a relatively complex toxicity profile, which may be a limitation of applicability. In a neoadjuvant setting, grade 3-4 adverse events were consistent with those reported in the original publication (8), mainly neutropenia (3-20\%, with a low rate of febrile neutropenia using granulocyte stimulating factors) and diarrhea $(\leq 18 \%)(60)$.

Pancreatoduodenectomy is associated with a high morbidity rate (30-60\%), and neoadjuvant therapy may put patients at a higher risk of complications such as wound infections, anastomotic leaks, intra-abdominal abscesses and mortality. The morbidity and mortality rates described in neoadjuvant studies are similar to those reported upon pancreatoduodenectomy in high-volume centers, suggesting that surgery subsequent to neoadjuvant chemotherapy is safe $(33,34,65)$. In particular, no fistulae, a major complication of PAC resection, were reported $(17,49)$. Although neoadjuvant therapy may allow resection in patients with an initially unresectable disease, the high incidence of recurrence, as in the present case, emphasizes the systemic behavior of the disease. This raises the question if palliative systemic chemotherapy and/or chemoradiation may achieve the same outcome, avoiding the morbidity and potential mortality of surgery (66). In the future, biomarkers may assist clinicians in decisional processes. For example, the DCP4 gene was revealed to be highly correlated with the presence of widespread metastasis but not with locally advanced tumors (67). In addition, in a series of 106 patients who underwent radical surgery, all of the 6 patients that achieved a 5-year survival exhibited intact SMAD4/DPC4 (68).

Finally, careful evaluation of histological changes subsequent to preoperative therapy is important to accurately assess treatment efficacy. Several variables of tumor response to neoadjuvant therapy have been proposed, including the number of severe degenerative cancer cells (SDCC), percentage of viable cells, degree of fibrosis or presence of necrosis $(69,70)$. In a trial using SDCC to evaluate response to preoperative therapy, no advantage in terms of OS was observed in 13/26 patients who achieved a major response, defined as $>80 \%$ SDCC (66). In trials where the percentage of remaining viable cells was evaluated, the patients whose tumors demonstrated minimal pathologic response exhibited more than twice the risk of mortality compared with patients who achieved a partial response or $\mathrm{pCR}(\mathrm{HR}=2.74 ; \mathrm{P}=0.01)$; although significant, this finding should be interpreted with caution, due to the small sample size $(37,39)$. In total, two trials correlated survival with the degree of fibrosis following neoadjuvant therapy, with conflicting results $(71,72)$. However, when the presence of tumor necrosis and fibrosis were analyzed, only tumor necrosis was observed to be an adverse prognostic factor (70). The College of American Pathologists has proposed a grading system for tumor response subsequent to neoadjuvant therapy: 0) Complete response, no viable cells; i) moderate response, single or small groups of cells; ii) minimal response, residual cancer outgrown by fibrosis; and iii) poor response, extensive residual cancer (67).

The significance and prognostic impact of pCR subsequent to neoadjuvant therapy for PAC is unclear. In malignancies such as rectal, esophageal and breast cancer, pCR has been associated with improved disease-free survival and OS (73-83). In PAC, a number of studies reported pathologic outcomes following neoadjuvant chemotherapy with or without fractionated radiotherapy or stereotactic body radiotherapy, and the pCR rate ranges between 2.4 and $32.0 \%$ (41,84-94). Two of these studies reported a significantly improved OS for patients who achieved pCR compared with that of patients who did not $(88,89)$, although this finding was not confirmed by a different study (90). In the aforementioned studies involving neoadjuvant FOLFIRINOX, no specific survival data were reported in patients who achieved pCR.

In conclusion, the present case considers certain current issues of neoadjuvant approaches for patients with BRPAC and LAPAC. Well-designed trials with standardized diagnostic, surgical and pathologic procedures are required to define the optimal treatment and the real clinical impact.

\section{References}

1. Siegel R, Ma JM, Zou ZH and Jemal A: Cancer statistics, 2014. Cancer J Clin 64: 9-29, 2014.

2. Hidalgo M: Pancreatic cancer. N Engl J Med 362: 1605-1617, 2010.

3. American Joint Committee on Cancer (AJCC) TNM staging system, September 6, 2013. American Cancer Society

4. Tamm EP, Silverman PM, Charnsangavej C and Evans DB: Diagnosis, staging, and surveillance of pancreatic cancer. AJR Am J Roentgenol 180: 1311-1323, 2003.

5. Varadachary GR, Tamm EP, Abbruzzese JL, Xiong HQ, Crane CH, Wang H, Lee JE, Pisters PW, Evans DB and Wolff RA: Borderline resectable pancreatic cancer: Definitions, management, and role of preoperative therapy. Ann Surg Oncol 13: 1035-1046, 2006.

6. Katz MH, Marsh R, Herman JM, Shi Q, Collison E, Venook AP, Kindler HL, Alberts SR, Philip P, Lowy AM, et al: Borderline resectable pancreatic cancer: Need for standardization and methods for optimal clinical trial design. Ann Surg Oncol 20: 2787-2795, 2013

7. Abrams RA, Lowy AM, O'Reilly EM, Wolff RA, Picozzi VJ and Pisters PW: Combined modality treatment of resectable and borderline resectable pancreas cancer: Expert consensus statement. Ann Surg Oncol 16: 1751-1756, 2009.

8. Conroy T, Desseigne F, Ychou M, Bouché O, Guimbaud R, Bécouarn Y, Adenis A, Raoul JL, Gourgou-Bourgade S, de la Fouchardière $\mathrm{C}$, et al: FOLFIRINOX versus gemcitabine for metastatic pancreatic cancer. N Engl J Med 364: 1817-1825, 2011.

9. Von Hoff DD, Ervin T, Arena FP, Chiorean EG, Infante J, Moore M, Seay T, Tjulandin SA, Ma WW, Saleh MN, et al: Increased survival in pancreatic cancer with nab-paclitaxel plus gemcitabine. N Engl J Med 369: 1691-1703, 2013.

10. Tempero MA, Malafa MP, Behrman, Benson AB III, Casper ES, Chiorean EG, Chung V, Cohen SJ, Czito B, Engebretson A, et al: Pancreatic adenocarcinoma, version 2.2014: Featured updates to the NCCN guidelines. J Natl Compr Canc Netw 12: 1083-1093, 2014. 
11. Valls C, Andía E, Sanchez A, Fabregat J, Pozuelo O, Quintero JC Serrano T, Garcia-Borobia F and Jorba R: Dual-phase helical CT of pancreatic adenocarcinoma: Assessment of resectability before surgery. AJR Am J Roentgenol 178: 821-826, 2002.

12. Legmann P, Vignaux O, Dousset B, Baraza AJ, Palazzo L, Dumontier I, Coste J, Louvel A, Roseau G, Couturier D and Bonnin A: Pancreatic tumors: Comparison of dual-phase helical CT and endoscopic sonography. AJR Am J Roentgenol 170: 1315-1322, 1998

13. DeWitt J, Devereaux B, Chriswell M, McGreevy K, Howard T, Imperiale TF, Ciaccia D, Lane KA, Maglinte D, Kopecky K, et al: Comparison of endoscopic ultrasonography and multidetector computed tomography for detecting and staging pancreatic cancer. Ann Intern Med 141: 753-763, 2004.

14. Michl P, Pauls S and Gress TM: Evidence-based diagnosis and staging of pancreatic cancer. Best Pract Res Clin Gastroenterol 20: $227-251,2006$.

15. Kim R, Prithviraj G, Kothari N, Springett G, Malafa M, Hodul P, Kim J, Yue B, Morse B and Mahipal A: PET/CT fusion scan prevents futile laparotomy in early stage pancreatic cancer. Clin Nucl Med 40: e501-e505, 2015.

16. Katz MH, Fleming JB, Bhosale P, Varadhachary G, Lee JE, Wolff R, Wang H, Abbruzzese J, Pisters PW, Vauthey JN, et al: Response of borderline resectable pancreatic cancer to neoadjuvant therapy is not reflected by radiographic indicators. Cancer 118: 5749-5756, 2012.

17. Ferrone CR, Marchegiani G, Hong TS, Ryan DP, Deshpande V, McDonnell EI, Sabbatino F, Santos DD, Allen JN, Blaszkowsky LS, et al: Radiological and surgical implications of neoadjuvant treatment with FOLFIRINOX for locally advanced and borderline resectable pancreatic cancer. Ann Surg 261: $12-17,2015$

18. Hsu CC, Wolfgang CL, Laheru DA, Pawlik TM, Swartz MJ, Winter JM, Robinson R, Edil BH, Narang AK, Choti MA, et al: Early mortality risk score: Identification of poor outcomes following upfront surgery for resectable pancreatic cancer. J Gastrointest Surg 16: 753-761, 2012.

19. Tzeng CW, Balachandran A, Ahmad M, Lee JE, Krishnan S, Wang $\mathrm{H}$, Crane $\mathrm{CH}$, Wolff RA, Varadhachary GR, Pisters PW, et al: Serum carbohydrate antigen 19-9 represents a marker of response to neoadjuvant therapy in patients with borderline resectable pancreatic cancer. HPB (Oxford) 16: 430-438, 2014

20. Iacobuzio-Donahue CA, Fu B, Yachida S, Luo M, Abe H, Henderson CM, Vilardell F, Wang Z, Keller JW, Banerjee P, et al: DPC4 gene status of the primary carcinoma correlates with patterns of failure in patients with pancreatic cancer. J Clin Oncol 27: 1806-1813, 2009.

21. Singh P, Wig JD, Srinivasan R and Radotra BD: A comprehensive examination of Smad4, Smad6 and Smad7 mRNA expression in pancreatic ductal adenocarcinoma. Indian J Cancer 48: 170-174, 2011.

22. Infante JR, Matsubayashi H, Sato N, Tonascia J, Klein AP, Riall TA, Yeo C, Iacobuzio-Donahue $C$ and Goggins $M$ Peritumoral fibroblast SPARC expression and patient outcome with resectable pancreatic adenocarcinoma. J Clin Oncol 25: 319-325, 2007

23. Miyoshi K, Sato N, Ohuchida K, Mizumoto K and Tanaka M: SPARC mRNA expression as a prognostic marker for pancreatic adenocarcinoma patients. Anticancer Res 30: 867-871, 2010.

24. Prenzel KL, Warnecke-Eberz U, Xi H, Brabender J, Baldus SE, Bollschweiler E, Gutschow CA, Hölscher AH and Schneider PM: Significant overexpression of SPARC/osteonectin mRNA in pancreatic cancer compared to cancer of the papilla of Vater. Oncol Rep 15: 1397-1401, 2006.

25. Nagaraju GP, Dontula R, El-Rayes BF and Lakka SS: Molecular mechanisms underlying the divergent roles of SPARC in human carcinogenesis. Carcinogenesis 35: 967-973, 2014

26. Desai NP, Trieu V, Hwang LY, Wu R, Soon-Shiong P and Gradishar WJ: Improved effectiveness of nanoparticle albumin-bound (nab) paclitaxel versus polysorbate-based docetaxel in multiple xenografts as a function of HER2 and SPARC status. Anticancer Drugs 19: 899-909, 2008.

27. Xiong HQ and Abbruzzese JL: Epidermal growth factor receptor-targeted therapy for pancreatic cancer. Semin Oncol 29 (5 Suppl 14): S31-S37, 2002.

28. Yamanaka Y, Friess H, Kobrin MS, Buchler M, Beger HG and Korc M: Coexpression of epidermal growth factor receptor and ligands in human pancreatic cancer is associated with enhanced tumor aggressiveness. Anticancer Res 13: 565-569, 1993.
29. Hu YC, Komorowski RA, Graewin S, Hostetter G, Kallioniemi OP, Pitt HA and Ahrendt SA: Thymidylate synthase expression predicts the response to 5-fluorouracil-based adjuvant therapy in pancreatic cancer. Clin Cancer Res 9: 4165-4171, 2003.

30. van der Zee JA, van Eijck $\mathrm{CH}$, Hop WC, van Dekken $\mathrm{H}$, Dicheva BM, Seynhaeve AL, Koning GA, Eggermont AM and Ten Hagen TL: Expression and prognostic significance of thymidylate synthase (TS) in pancreatic head and periampullary cancer. Eur J Surg Oncol 38: 1058-1064, 2012.

31. Jin K, Luo G, Xiao Z, Liu Z, Liu C, Ji S, Xu J, Liu L, Long J, Ni Q and $\mathrm{Yu} X$ : Noncoding RNAs as potential biomarkers to predict the outcome in pancreatic cancer. Drug Des Devel Ther 9: $1247-1255,2015$

32. Ansari D, Gustafsson A and Andersson R: Update on the management of pancreatic cancer: Surgery is not enough. World J Gastroenterol 21: 3157-3165, 2015.

33. Evans DB, Varadhachary GR, Crane CH, Sun CC, Lee JE, Pisters PW, Vauthey JN, Wang H, Cleary KR, Staerkel GA, et al: Preoperative gemcitabine-based chemoradiation for patients with resectable adenocarcinoma of the pancreatic head. J Clin Oncol 26: 3496-3502, 2008

34. Varadhachary GR, Wolff RA, Crane CH, Sun CC, Lee JE, Pisters PW, Vauthey JN, Abdalla E, Wang H, Staerkel GA, et al: Preoperative gemcitabine and cisplatin followed by gemcitabine-based chemoradiation for resectable adenocarcinoma of the pancreatic head. J Clin Oncol 26: 3487-3495, 2008.

35. Cho SW, Tzeng CW, Johnston WC, Cassera MA, Newell PH, Hammill CW, Wolf RF, Aloia TA and Hansen PD: Neoadjuvant radiation therapy and its impact on complications after pancreaticoduodenectomy for pancreatic cancer: Analysis of the American College of Surgeons National Surgical Quality Improvement Program (ACS-NSQIP). HPB (Oxford) 16: 350-356, 2014.

36. Lind PA, Isaksson B, Almström M, Johnsson A, Albiin N, Byström P and Permert J: Efficacy of preoperative radiochemotherapy in patients with locally advanced pancreatic carcinoma. Acta Oncol 47: 413-420, 2008.

37. Evans DB, Rich TA, Byrd DR, Cleary KR, Connelly JH, Levin B, Charnsangavej $\mathrm{C}$, Fenoglio $\mathrm{CJ}$ and Ames FC: Preoperative chemoradiation and pancreaticoduodenectomy for adenocarcinoma of the pancreas. Arch Surg 127: 1335-1339, 1992.

38. Abbott DE, Tzeng CW, Merkow RP, Cantor SB, Chang GJ, Katz MH, Bentrem DJ, Bilimoria KY, Crane $\mathrm{CH}$, Varadhachary GR, et al: The cost-effectiveness of neoadjuvant chemoradiation is superior to a surgery-first approach in the treatment of pancreatic head adenocarcinoma. Ann Surg Oncol 20 (Suppl 3): S500-S5008, 2013.

39. Katz MH, Pisters PW, Evans DB, Sun CC, Lee JE, Fleming JB, Vauthey JN, Abdalla EK, Crane CH, Wolff RA, et al: Borderline resectable pancreatic cancer: The importance of this emerging stage of disease. J Am Coll Surg 206: 833-848, 2008.

40. Chun YS, Milestone BN, Watson JC, Cohen SJ, Burtness B, Engstrom PF, Haluszka O, Tokar JL, Hall MJ, Denlinger CS, et al: Defining venous involvement in borderline resectable pancreatic cancer. Ann Surg Oncol 17: 2832-2838, 2010.

41. Rose JB, Rocha FG, Alseidi A, Biehl T, Moonka R, Ryan JA, Lin B, Picozzi V and Helton S: Extended neoadjuvant chemotherapy for borderline resectable pancreatic cancer demonstrates promising postoperative outcomes and survival. Ann Surg Oncol 21: 1530-1537, 2014.

42. Takahashi H, Ohigashi H, Gotoh K, Marubashi S, Yamada T, Murata $M$, Ioka T, Uehara $H$, Yano $M$ and Ishikawa $O$ : Preoperative gemcitabine-based chemoradiation therapy for resectable and borderline resectable pancreatic cancer. Ann Surg 258: 1040-1050, 2013

43. Mahaseth H, Brutcher E, Kauh J, Hawk N, Kim S, Chen Z, Kooby DA, Maithel SK, Landry J and El-Rayes BF: Modified FOLFIRINOX regimen with improved safety and maintained efficacy in pancreatic adenocarcinoma. Pancreas 42: 1311-1315, 2013.

44. Boone BA, Steve J, Krasinskas AM, Zureikat AH,Lembersky BC, Gibson MK, Stoller RG, Zeh HJ and Bahary N: Outcomes with FOLFIRINOX for borderline resectable and locally unresectable pancreatic cancer. J Surg Oncol 108: 236-241, 2013.

45. Gunturu KS, Yao X, Cong X, Thumar JR, Hochster HS, Stein SM and Lacy J: FOLFIRINOX for locally advanced and metastatic pancreatic cancer: Single institution retrospective review of efficacy and toxicity. Med Oncol 30: 361, 2013.

46. Peddi PF, Lubner S, McWilliams R, Tan BR, Picus J, Sorscher SM, Suresh R, Lockhart AC, Wang J, Menias C, et al: Multi-institutional experience with FOLFIRINOX in pancreatic adenocarcinoma. JOP 13: 497-501, 2012. 
47. Hosein PJ, Macintyre J, Kawamura C, Maldonado JC, Ernani V, Loaiza-Bonilla A, Narayanan G, Ribeiro A, Portelance L, Merchan JR, et al: A retrospective study of neoadjuvant FOLFIRINOX in unresectable or borderline-resectable locally advanced pancreatic adenocarcinoma. BMC Cancer 12: 199, 2012.

48. Tinchon C, Hubmann E, Pichler A, Keil F, Pichler M, Rabl H, Uggowitzer M, Jilek K, Leitner G and Bauernhofer T: Safety and efficacy of neoadjuvant FOLFIRINOX treatment in a series of patients with borderline resectable pancreatic ductal adenocarcinoma. Acta Oncol 52: 1231-1233, 2013.

49. Christians KK, Tsai S, Mahmoud A, Ritch P, Thomas JP, Wiebe L, Kelly T, Erickson B, Wang H, Evans DB and George B: Neoadjuvant FOLFIRINOX for borderline resectable pancreas cancer: A new treatment paradigm? Oncologist 19: 266-274, 2014.

50. Faris JE, Blaszkowsky LS, McDermott S, Guimaraes AR, Szymonifka J, Huynh MA, Ferrone CR, Wargo JA, Allen JN, Dias LE, et al: FOLFIRINOX in locally advanced pancreatic cancer: The Massachusetts General Hospital Cancer Center experience. Oncologist 18: 543-548, 2013.

51. James ES, Yao X, Cong X, Li J, Hahn C, Kaley K, Kortmansky JS, Fischbach NA, Chang BW, Salem RR, et al: Interim analysis of a phase II study of dose-modified FOLFIRINOX (mFOLFIRINOX) in locally advanced (LAPC) and metastatic pancreatic cancer (MPC). J Clin Oncol 32 (Suppl): e15226, 2014.

52. Hazariwala R, Landry J, El-Reyes B, et al: Neoadjuvant FOLFIRINOX and radiation therapy improves resectability of pancreatic adenocarcinoma. Int J Radiat Oncol Biol Phys 2 (Suppl 1): 87, 2013.

53. Vasile E, De Lio N, Cappelli C, et al: Phase II study of neoadjuvant chemotherapy with modified FOLFOXIRI in borderline resectable or unresectable stage III pancreatic cancer. J Clin Oncol;15 (Suppl 1): 31, 2013.

54. Kharofa J, Kelly TR, Ritch PS, George B, Wiebe LA, Thomas JP, Christians KK, Evans DP and Erickson B: 5-FU/leucovorin, irinotecan, oxaliplatin (FOLFIRINOX) induction followed by chemoXRT in borderline resectable pancreatic cancer. J Clin Oncol 30 (Suppl): e14613, 2012.

55. Lowery MA, Yu KH, Adel NG, Apollo AJ, Boyar MS, Caron P, Ilson D, Segal NH, Janjigian YY, Janjigian DR, et al: Activity of front-line FOLFIRINOX (FFX) in stage III/IV pancreatic adenocarcinoma (PC) at Memorial Sloan-Kettering Cancer Center (MSKCC). J Clin Oncol 30 (Suppl): 4057, 2012.

56. Blazer M, Wu C, Goldberg RM, Phillips G, Schmidt C, Muscarella P, Wuthrick E, Williams TM, Reardon J, Ellison EC, et al: Neoadjuvant modified (m) FOLFIRINOX for locally advanced unresectable (LAPC) and borderline resectable (BRPC) adenocarcinoma of the pancreas. Ann Surg Oncol 22: $1153-1159,2015$

57. Nanda RH, El-Rayes B, Maithel SK and Landry J: Neoadjuvant modified FOLFIRINOX and chemoradiation therapy for locally advanced pancreatic cancer improves resectability. J Surg Oncol 111: 1028-1034, 2015.

58. Paniccia A, Edil BH, Schulick RD, Byers JT, Meguid C, Gajdos C and McCarter MD: Neoadjuvant FOLFIRINOX application in borderline resectable pancreatic adenocarcinoma: A retrospective cohort study. Medicine (Baltimore) 93: e198, 2014

59. Mellon EA, Hoffe SE, Springett GM, Frakes JM, Strom TJ, Hodul PJ, Malafa MP, Chuong MD and Shridhar R: Long-term outcomes of induction chemotherapy and neoadjuvant stereotactic body radiotherapy for borderline resectable and locally advanced pancreatic adenocarcinoma. Acta Oncol 54: 979-985, 2015.

60. Petrelli F, Coinu A, Borgonovo K, Cabiddu M, Ghilardi M, Lonati V, Aitini E and Barni S; Gruppo Italiano per lo Studio dei Carcinomi dell'Apparato Digerente (GISCAD): FOLFIRINOX-based neoadjuvant therapy in borderline resectable or unresectable pancreatic cancer: A meta-analytical review of published studies. Pancreas 44: 515-521, 2015.

61. Oettle H, Post S, Neuhaus P, Gellert K, Langrehr J, Ridwelski K, Schramm H, Fahlke J, Zuelke C, Burkart C, et al: Adjuvant chemotherapy with gemcitabine vs observation in patients undergoing curative-intent resection of pancreatic cancer: A randomized controlled trial. JAMA 297: 267-277, 2007.

62. Neoptolemos JP, Stocken DD, Bassi C, Ghaneh P, Cunningham D, Goldstein D, Padbury R, Moore MJ, Gallinger S, Mariette C, et al: Adjuvant chemotherapy with fluorouracil plus folinic acid vs gemcitabine following pancreatic cancer resection: A randomized controlled trial. JAMA 304: 1073-1081, 2010.
63. Katz MH, Shi Q, Ahmad SA, Herman JM, de Marsh RW, Collisson EA, Schwartz LH, Martin RC, Conway WC, Truty M, et al: Preoperative modified FOLFIRINOX (mFOLFIRINOX) followed by chemoradiation (CRT) for borderline resectable (BLR) pancreatic cancer (PDAC): Initial results from Alliance Trial A021101. J Clin Oncol 33 (Suppl; abstr 4008), 2015.

64. Pancreatic Resectability in Cancers With Known Limited Extension (PRICKLE)-A Single-centre Phase 2a Study of Gemcitabine Plus Nab-paclitaxel for Borderline Unresectable Locally Advanced Pancreatic Cancer. ClinicalTrials.gov Identifier: NCT02124369, 2017.

65. Breslin TM, Hess KR, Harbison DB, Jean ME, Cleary KR, Dackiw AP, Wolff RA, Abbruzzese JL, Janjan NA, Crane $\mathrm{CH}$, et al: Neoadjuvant chemoradiotherapy for adenocarcinoma of the pancreas: Treatment variables and survival duration. Ann Surg Oncol 8: 123-132, 2001.

66. Ishikawa O, Ohhigashi H, Teshima T, Chatani M, Inoue $\mathrm{T}$, Tanaka S, Kitamura T, Wada A, Sasaki Y, Imaoka S, et al: Clinical and histopathological appraisal of preoperative irradiation for adenocarcinoma of the pancreatoduodenal region. J Surg Oncol 40: 143-151, 1989.

67. Washington K, Berlin J and Branton P: Protocol for the examination of specimens from patients with carcinoma of the exocrine pancreas: Protocol applies to all epithelial tumors of the exocrine pancreas. Endocrine tumors and tumors of the ampulla of Vater are not included. Northfield, IL: College of American Pathologists, 2010.

68. Oshima M, Okano K, Muraki S, Haba R, Maeba T, Suzuki Y and Yachida S: Immunohistochemically detected expression of 3 major genes (CDKN2A/p16, TP53, and SMAD4/DPC4) strongly predicts survival in patients with resectable pancreatic cancer. Ann Surg 258: 336-346, 2013.

69. Pendurthi TK, Cooper HS, Young NA, et al: Histopathologic effects of preoperative chemoradiotheraoy on pancreatic carcinoma. Gastroenterology 110: A1410-A1410, 1996.

70. White RR, Xie HB, Gottfried MR, Czito BG, Hurwitz HI, Morse MA, Blobe GC, Paulson EK, Baillie J, Branch MS, et al: Significance of histological response to preoperative chemoradiotherapy for pancreatic cancer. Ann Surg Oncol 12: 214-221, 2005.

71. Sasson AR, Wetherington RW, Hoffman JP, Ross EA, Cooper H, Meropol NJ, Freedman G, Pingpank JF and Eisenberg BL: Neoadjuvant chemoradiotherapy for adenocarcinoma of the pancreas: Analysis of histopathology and outcome. Int J Gastrointest Cancer 34: 121-128, 2003.

72. Hoffman JP, Weese JL, Solin LJ, Engstrom P, Agarwal P, Barber LW, Guttmann MC, Litwin S, Salazar H and Eisenberg BL: A pilot study of preoperative chemoradiation for patients with localized adenocarcinoma of the pancreas. Am J Surg 169: 71-78, 1995.

73. Aschele C, Cionini L, Lonardi S, Pinto C, Cordio S, Rosati G, Artale S, Tagliagambe A, Ambrosini G, Rosetti P, et al: Primary tumor response to preoperative chemoradiation with or without oxaliplatin in locally advanced rectal cancer: Pathologic results of the STAR-01 randomized phase III trial. J Clin Oncol 29: 2773-2780, 2011.

74. García-Aguilar J, Hernandez de Anda E, Sirivongs P, Lee SH, Madoff RD and Rothenberger DA: A pathologic complete response to preoperative chemoradiation is associated with lower local recurrence and improved survival in rectal cancer patients treated by mesorectal excision. Dis Colon Rectum 46: 298-304, 2003

75. Martin ST, Heneghan HM and Winter DC: Systematic review and meta-analysis of outcomes following pathological complete response to neoadjuvant chemoradiotherapy for rectal cancer. $\mathrm{Br}$ J Surg 99: 918-928, 2012.

76. Maas M, Nelemans PJ, Valentini V, Das P, Rödel C, Kuo LJ, Calvo FA, García-Aguilar J, Glynne-Jones R, Haustermans $\mathrm{K}$, et al: Long-term outcome in patients with a pathological complete response after chemoradiation for rectal cancer: A pooled analysis of individual patient data. Lancet Oncol 11: 835-844, 2010.

77. Meredith KL, Weber JM, Turaga KK, Siegel EM, McLoughlin J, Hoffe S, Marcovalerio M, Shah N, Kelley S and Karl R: Pathologic response after neoadjuvant therapy is the major determinant of survival in patients with esophageal cancer. Ann Surg Oncol 17: 1159-1167, 2010.

78. Pasini F, de Manzoni G, Zanoni A, Grandinetti A, Capirci C, Pavarana M, Tomezzoli A, Rubello D and Cordiano C: Neoadjuvant therapy with weekly docetaxel and cisplatin, 5-fluorouracil continuous infusion, and concurrent radiotherapy in patients with locally advanced esophageal cancer produced a high percentage of long-lasting pathological complete response: A phase 2 study. Cancer 119: 939-945, 2013. 
79. Rohatgi P, Swisher SG, Correa AM, Wu TT, Liao Z, Komaki R, Walsh GL, Vaporciyan AA, Rice DC, Roth JA and Ajani JA: Characterization of pathologic complete response after preoperative chemoradiotherapy in carcinoma of the esophagus and outcome after pathologic complete response. Cancer 104: 2365-2372, 2005.

80. Berger AC, Farma J, Scott WJ, Freedman G, Weiner L, Cheng JD, Wang $\mathrm{H}$ and Goldberg $\mathrm{M}$ : Complete response to neoadjuvant chemoradiotherapy in esophageal carcinoma is associated with significantly improved survival. J Clin Oncol 23: 4330-4337, 2005.

81. Vallböhmer D, Hölscher AH, DeMeester S, DeMeester T, Salo J, Peters J, Lerut T, Swisher SG, Schröder W, Bollschweiler E and Hofstetter W: A multicenter study of survival after neoadjuvant radiotherapy/chemotherapy and esophagectomy for ypT0N0M0R0 esophageal cancer. Ann Surg 252: 744-749, 2010.

82. Symmans WF, Peintinger F, Hatzis C, Rajan R, Kuerer H, Valero V, Assad L, Poniecka A, Hennessy B, Green M, et al: Measurement of residual breast cancer burden to predict survival after neoadjuvant chemotherapy. J Clin Oncol 25: 4414-4422, 2007.

83. Adams S, Chakravarthy AB, Donach M, Spicer D, Lymberis S, Singh B, Bauer JA, Hochman T, Goldberg JD, Muggia F, et al: Preoperative concurrent paclitaxel-radiation in locally advanced breast cancer: Pathologic response correlates with five-year overall survival. Breast Cancer Res Treat 124: 723-732, 2010.

84. Sherman WH, Chu K, Chabot J, Allendorf J, Schrope BA Hecht E, Jin B, Leung D, Remotti H, Addeo G, et al: Neoadjuvant gemcitabine, docetaxel, and capecitabine followed by gemcitabine and capecitabine/radiation therapy and surgery in locally advanced, unresectable pancreatic adenocarcinoma Cancer 121: 673-680, 2015.

85. Boone BA, Steve J, Zenati MS, Hogg ME, Singhi AD, Bartlett DL, Zureikat AH, Bahary N and Zeh HJ III: Serum CA 19-9 response to neoadjuvant therapy is associated with outcome in pancreatic adenocarcinoma. Ann Surg Oncol 21: 4351-4358, 2014.

86. Rajagopalan MS, Heron DE, Wegner RE, Zeh HJ, Bahary N, Krasinskas AM,Lembersky B, Brand R, Moser AJ, Quinn AE and Burton SA: Pathologic response with neoadjuvant chemotherapy and stereotactic body radiotherapy for borderline resectable and locally-advanced pancreatic cancer. Radiat Oncol 8: 254, 2013.
87. Lee JL, Kim SC, Kim JH, Lee SS, Kim TW, Park DH, Seo DW, Lee SK, Kim MH, Kim JH, et al: Prospective efficacy and safety study of neoadjuvant gemcitabine with capecitabine combination chemotherapy for borderline-resectable or unresectable locally advanced pancreatic adenocarcinoma. Surgery 152: 851-862, 2012.

88. Zhao Q, Rashid A, Gong Y, Katz MH, Lee JE, Wolf R, Balachandran A, Varadhachary GR, Pisters PW, Wang H, et al: Pathologic complete response to neoadjuvant therapy in patients with pancreatic ductal adenocarcinoma is associated with a better prognosis. Ann Diagn Pathol 16: 29-37, 2012.

89. Chatterjee D, Katz MH, Rashid A, Varadhachary GR, Wolff RA, Wang H, Lee JE, Pisters PW, Vauthey JN, Crane C, et al: Histologic grading of the extent of residual carcinoma following neoadjuvant chemoradiation in pancreatic ductal adenocarcinoma: A predictor for patient outcome. Cancer 118: 3182-3190, 2012.

90. Barugola G, Partelli S, Crippa S, Capelli P, D'Onofrio M, Pederzoli P and Falconi M: Outcomes after resection of locally advanced or borderline resectable pancreatic cancer after neoadjuvant therapy. Am J Surg 203: 132-139, 2012.

91. Le Scodan R, Mornex F, Partensky C, Mercier C, Valette PJ, Ychou M, Bibeau F and Scoazec JY: Histologic assessment of treatment effect of preoperative chemoradiation in patients presenting with resectable pancreatic adenocarcinoma. Cancer Radiother 15: 97-105, 2011.

92. Turrini O, Ychou M, Moureau-Zabotto L, Rouanet P, Giovannini M, Moutardier V, Azria D, Delpero JR and Viret F: Neoadjuvant docetaxel-based chemoradiation for resectable adenocarcinoma of the pancreas: New neoadjuvant regimen was safe and provided an interesting pathologic response. Eur J Surg Oncol 36: 987-92, 2010.

93. Magnin V, Moutardier V, Giovannini MH, Lelong B, Giovannini M, Viret F, Monges G, Bardou VJ, Alzieu C and Delpero JR: Neoadjuvant preoperative chemoradiation in patients with pancreatic cancer. Int J Radiat Oncol Biol Phys 55: 1300-1304, 2003.

94. Wanebo HJ, Glicksman AS, Vezeridis MP, Clark J, Tibbetts L, Koness RJ and Levy A: Preoperative chemotherapy, radiotherapy, and surgical resection of locally advanced pancreatic cancer. Arch Surg 135: 81-88, 2000. 